\title{
New carnivorous dinosaur from the Late Cretaceous of NW Patagonia and the evolution of abelisaurid theropods
}

\author{
Juan I. Canale • Carlos A. Scanferla • \\ Federico L. Agnolin • Fernando E. Novas
}

Received: 14 July 2008 /Revised: 17 November 2008 / Accepted: 20 November 2008

(C) Springer-Verlag 2008

\begin{abstract}
A nearly complete skeleton of the new abelisaurid Skorpiovenator bustingorryi is reported here. The holotype was found in Late Cenomanian-Early Turonian outcrops of NW Patagonia, Argentina. This new taxon is deeply nested within a new clade of South American abelisaurids, named Brachyrostra. Within brachyrostrans, the skull shortening and hyperossification of the skull roof appear to be correlated with a progressive enclosure of the orbit, a set of features possibly related to shock-absorbing
\end{abstract}

Communicated by G. Mayr

Electronic supplementary material The online version of this article (doi:10.1007/s00114-008-0487-4) contains supplementary material, which is available to authorized users.

J. I. Canale $\cdot$ C. A. Scanferla $\cdot$ F. E. Novas

CONICET,

Consejo Nacional de Investigaciones Científicas y Técnicas,

Buenos Aires, Argentina

F. E. Novas

e-mail: fernovas@yahoo.com.ar

J. I. Canale ( $\bowtie)$

Museo Municipal "Ernesto Bachmann",

Dr. Natali S/N Villa El Chocón,

Neuquén, Argentina

e-mail: juanignaciocanale@yahoo.com.ar

C. A. Scanferla • F. L. Agnolin • F. E. Novas

Museo Argentino de Ciencias Naturales "Bernardino Rivadavia",

Av. Angel Gallardo 470,

1405 Buenos Aires, Argentina

F. L. Agnolin

Área Paleontología. Fundación de Historia Natural "Félix de

Azara", Departamento de Ciencias Naturales y Antropología,

CEBBAD_Universidad Maimónides,

Valentín Virasoro 732,

C1405BDB Buenos Aires, Argentina capabilities. Moreover, the development of horn-like structures and differential cranial thickening appear to be convergently acquired within Abelisauridae. Based on the similarities between Skorpiovenator and carcharodontosaurid tooth morphology, we suggest that isolated teeth originally referred as post-Cenomanian Carcharodontosauridae most probably belong to abelisaurids.

Keywords Patagonia - Cretaceous · Theropoda . Abelisauridae

\section{Introduction}

The Abelisauridae represent a Cretaceous radiation of ceratosaurian theropods constituting the most diverse and best-known group of predatory dinosaurs from Gondwana (Bonaparte 1991), including taxa discovered from several localities in South America (i.e. Abelisaurus comahuensis Bonaparte and Novas 1985, Carnotaurus sastrei Bonaparte et al. 1990, Aucasaurus garridoi Coria et al. 2002, Ekrixinatosaurus novasi Calvo et al. 2004, Ilokelesia aguadagrandensis Coria and Salgado 2000, Pycnonemosaurus nevesi Kellner and Campos 2002), Africa (i.e. Rugops primus Sereno et al. 2004), Madagascar (i.e. Majungasaurus crenatissimus Krause et al. 2007) and India (i.e. Indosaurus matleyi Carrano and Sampson 2008). Although represented by relatively well-known skeletons, the phylogenetic relationships within abelisaurids remain debated (Coria and Salgado 2000; Coria et al. 2002; Carrano et al. 2002; Carrano and Sampson 2008). Here, we describe a new member of the group, Skorpiovenator bustingorryi gen. et sp. nov., from Late Cenomanian-Early Turonian strata of Patagonia, Argentina (Fig. 1a), which 


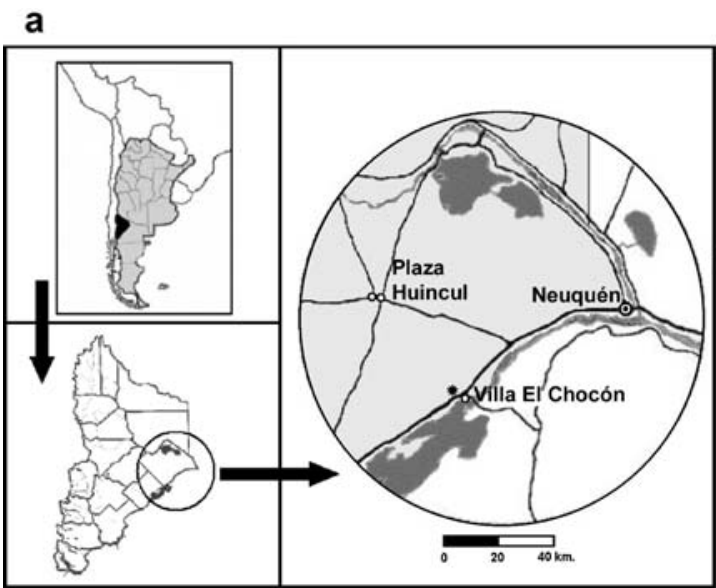

b

C

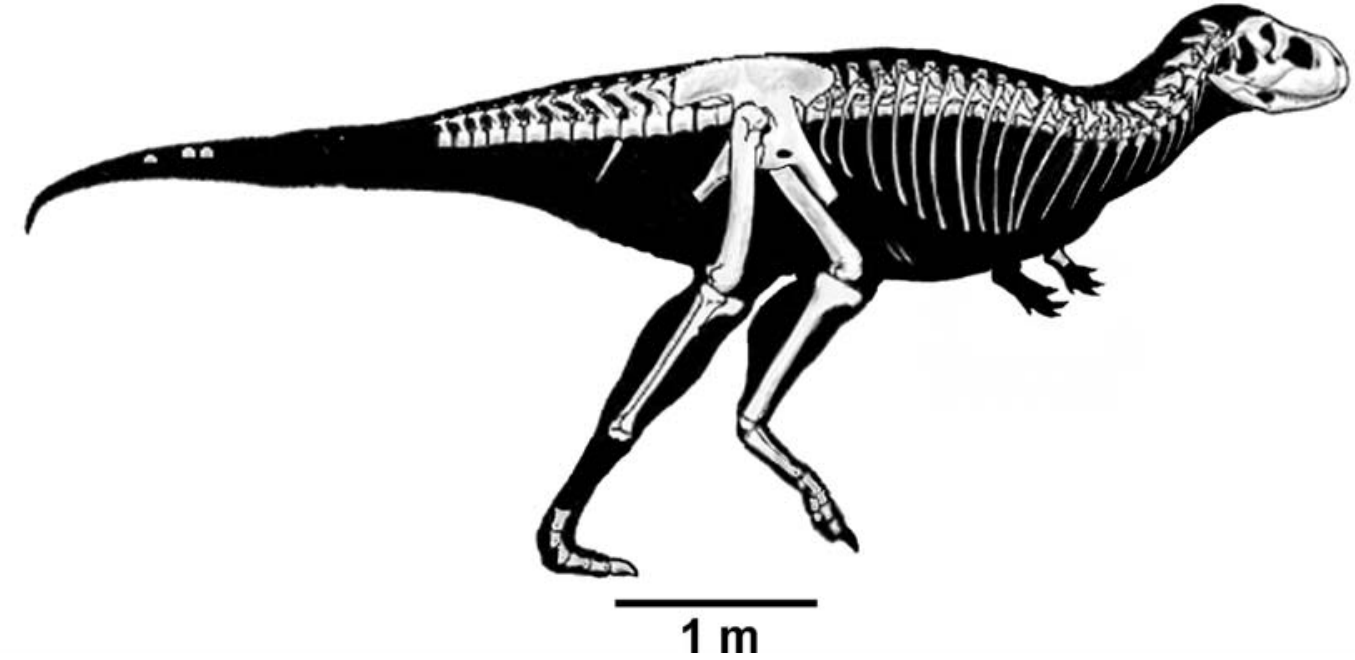

Fig. 1 a Location map showing the site of the finding near El Chocón town, indicated with a star. b Articulated skeleton of Skorpiovenator bustingorryi, still in the plaster jacket. c Skeletal anatomy of S. bustingorryi, reconstruction of right lateral view

offers new insights into the systematics and evolution of this group of meat-eating dinosaurs.

\section{Taxonomy}

Theropoda Marsh 1881

Ceratosauria Marsh 1884

Abelisauroidea Bonaparte 1991

Abelisauridae Bonaparte and Novas 1985

Carnotaurinae Sereno 1998

Brachyrostra new clade

S. bustingorryi gen. et sp. nov.

\section{Etymology}

The generic name derives from the Latin words skorpios (scorpion) and venator (hunter) because of the abundance of living scorpions moving around the excavation. The specific name honours the late Manuel Bustingorry, owner of the farm where the specimen was excavated.

\section{Holotype}

MMCH-PV 48 (Museo Municipal "Ernesto Bachmann", Villa El Chocón, Neuquén, Argentina): an articulated skeleton (Fig. 1b, c) represented by an almost complete skull and mandibles and most of the postcranial bones, lacking the right forearm and the distal half of the tail.

\section{Locality and horizon}

Bustingorry's farm, $3 \mathrm{~km}$ NW of Villa El Chocón, Neuquén Province, NW Patagonia, Argentina (Fig. 1a). The specimen was found in fluvial sandstones with intercalated mudstones, belonging to the lower levels of the Huincul Formation (Late Cenomanian-Early Turonian; Corbella et 
al. 2004). This formation has yielded other theropod taxa, including the carcharodontosaurid Mapusaurus roseae (Coria and Currie 2006) and the abelisaurid I. aguadagrandensis (Coria and Salgado 2000). Skorpiovenator differs from the latter taxon in the morphology of the postorbital and quadrate bones (see below).

Diagnosis Skorpiovenator is distinguished from other abelisaurids on the basis of the following unique traits: (1) ascending process of maxilla homogeneously wide rostrocaudally, (2) maxillary horizontal ramus dorsoventrally deep with subparallel dorsal and ventral margins, (3) maxilla/jugal contact subvertical, (4) 19 maxillary teeth, (5) lacrimal rostrally projected and with well-developed suborbital process, (6) quadratojugal with pronounced caudal notch, (7) dentary with caudoventral process bifurcated to receive rostral end of angular, and (8) angular with rostral end dorsoventrally deep to fit between splenial and prearticular.

\section{Description}

The preserved length of the skeleton (taken from the premaxilla to the 12th caudal vertebra) is $4.35 \mathrm{~m}$, thereby allowing a total length estimate of $\sim 6 \mathrm{~m}$ for the complete skeleton (Fig. 1c). The skull (Fig. 2a, b) is strongly ornamented with ridges, furrows and tubercles, features that typically occur in abelisaurids. It is craniocaudally short, similar to Carnotaurus (Bonaparte et al. 1990), being shorter and deeper than the skulls of Abelisaurus and Majungasaurus (Bonaparte and Novas 1985; Sampson et al. 1998). Notably, the maxilla and lacrimal of Skorpiovenator are wider than in the corresponding bones of the remaining abelisaurids. The antorbital fossa of the ascending ramus of the maxilla is less developed than in other abelisauroids (i.e. Noasaurus, Ekrixinatosaurus). The jugal is as deep as in Carnotaurus (Bonaparte et al. 1990). The lacrimal is strongly sigmoid in lateral view and shows a ventrally located suborbital process. Interestingly, the lacrimal bears a well-developed rostral process for articulation with the nasal, a plesiomorphic trait that is absent in the remaining abelisaurids. The orbits are ventrally enclosed by the suborbital flange of the postorbital, which is almost in contact with the lacrimal. The postorbital has a strongly inflated and ornamented dorsal border similar to Ekrixinatosaurus and contrasting with the shelf-like morphology of Ilokelesia. Like in Ekrixinatosaurus, the postorbital and squamosal are caudoventrally vaulted. As in other abelisaurids, the articular condyles of the quadrate are well developed and subequal in size, whereas in Ilokelesia, the lateral condyle is much more reduced than the medial one.
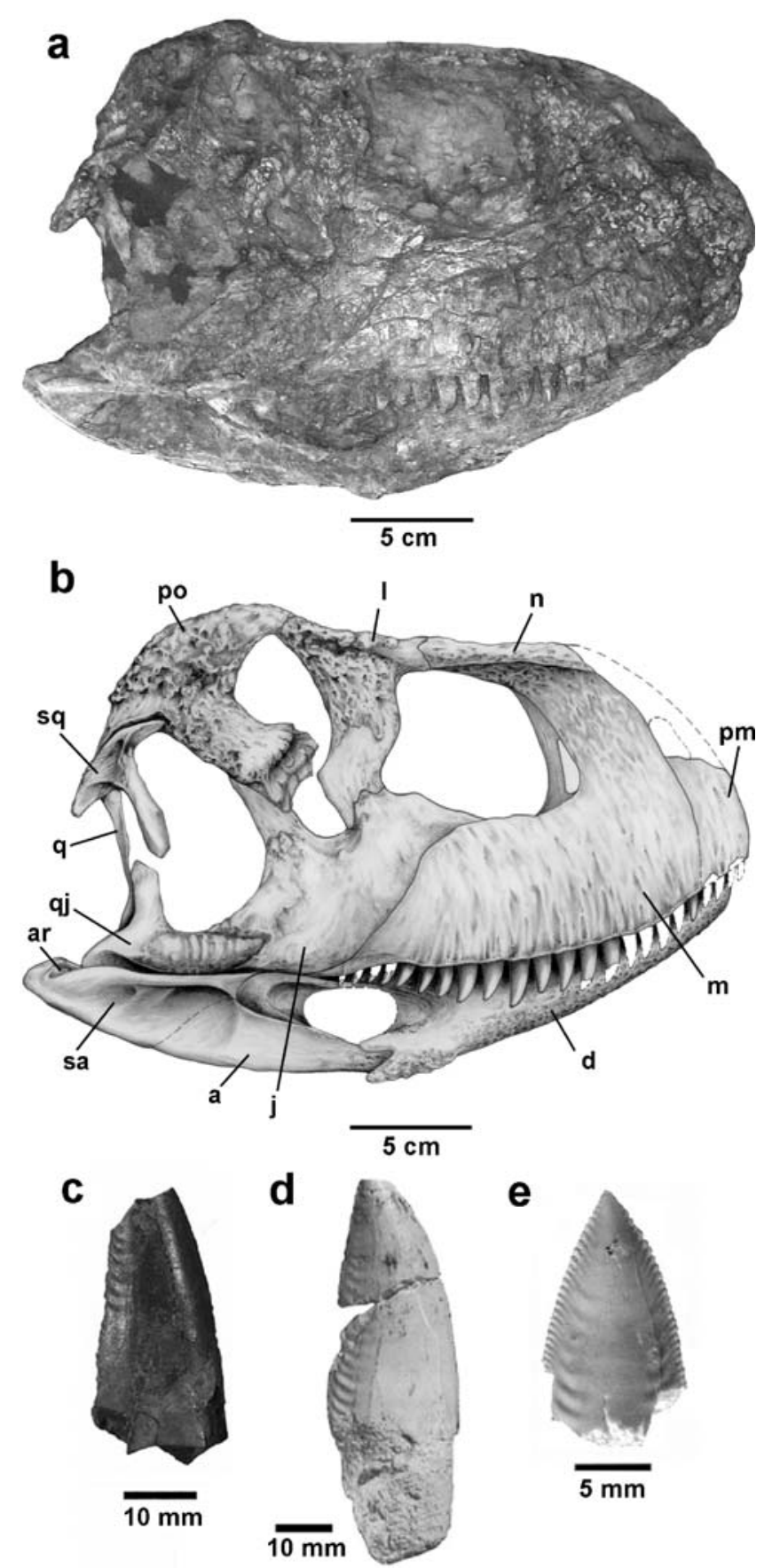

Fig. 2 Complete skull and jaws of S. bustingorryi. a Photograph. b Drawing with bone references. c Skorpiovenator, single tooth. d Supposed carcharodontosaurid tooth (taken from Candeiro et al. 2006). e Supposed carcharodontosaurid tooth (taken from Martinelli and Forasiepi 2004). $d$ Dentary, $a$ angular, sa surangular, ar articular, pm premaxilla, $m$ maxilla, $n$ nasal, $j$ jugal, $l$ lachrymal, po postorbital, $q j$ quadratojugal, $q$ quadrate, $s q$ squamosal

The contact zone between the dentary and postdentary bones is extensive; thus, the mandibular fenestra is smaller than in other abelisaurids (e.g. Carnotaurus, Majungasaurus; Bonaparte et al. 1990; Sampson et al. 1998). The caudoventral process of the dentary bifurcates 
to receive the angular, a feature not reported before from abelisaurids.

The number of maxillary teeth is 19 , which is more than in other known abelisaurids (Sampson and Witmer 2007). The general shape of the crowns is similar to other abelisaurids (i.e. Majungasaurus), with strongly curved mesial margins and straight distal margins (Smith, 2007). Arcuate enamel wrinkles are present next to the marginal serrations (Fig. 2c), a condition resembling carcharodontosaurid allosauroids (Sereno et al. 1996). The maxillary and dentary teeth exhibit shallow blood grooves.

The postcranial axial skeleton of Skorpiovenator was found in articulation up to the 12th caudal vertebra. The dorsal and sacral vertebrae are complete, but remain unprepared. The cervical vertebrae have hypertrophied epipophyses, but without the cranial processes reported in Carnotaurus, Noasaurus and Aucasaurus (Bonaparte 1991; Coria et al. 2002). The ribs of the cranial cervicals are devoid of foramina and bear proximal aliform expansions and rod-like distal shafts. As in Majungasaurus and Carnotaurus (O'Connor 2007), the aliform process is distally separated from the shaft by a deep notch.

The caudal vertebrae exhibit typical abelisaurid traits, such as large and distally expanded fan-shaped transverse process, with a slender anterior projection that contacts the transverse process of the preceding proximal caudal (Coria et al. 2002). The proximal caudals bear horizontally projected transverse processes, in contrast to the condition present in Carnotaurus and Aucasaurus, for example, where the transverse processes are laterodorsally directed.

The ilium has a continuously convex dorsal margin, in contrast to Aucasaurus and Carnotaurus in which this bone exhibits a straight dorsal margin. The femur is a stout bone, as in most abelisaurids, bearing a conspicuous large mediodistal crest on the distal end. Metatarsals II-IV are subparallel to each other, in contrast to Majungasaurus where metatarsal IV is distally divergent (Carrano 2007).

\section{Discussion}

Skorpiovenator is one of the most complete and informative abelisaurids yet known. The almost complete and articulated skeleton of this new taxon offers valuable osteological details that help to clarify character distribution among abelisaurid theropods.

The phylogenetic analysis conducted herein (Fig. 3 a) supports a clade of South American abelisaurids that

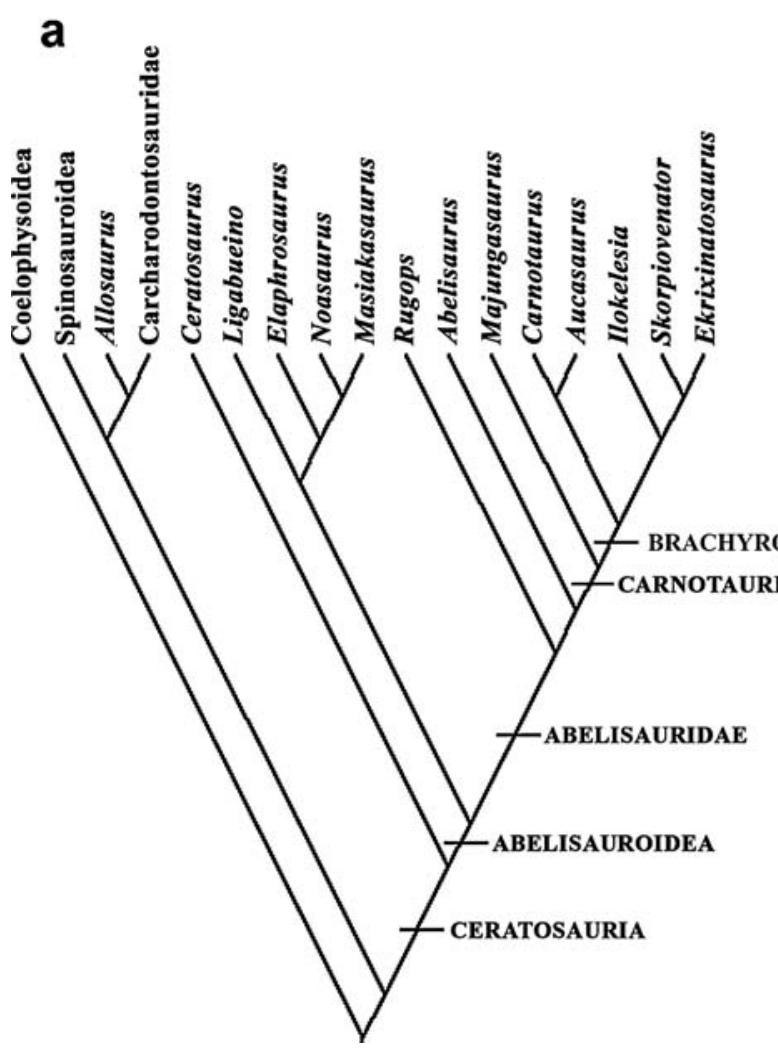

Fig. 3 a Consensus cladogram depicting phylogenetic relationships of S. bustingorryi within Theropoda. A dataset of 17 taxa and 113 characters was analysed using TNT 1.0, resulting in a single most parsimonious tree $(\mathrm{L}=171 ; \mathrm{CI}=0.69$; $\mathrm{RI}=0.826$; See $\mathrm{S} 1$ for Phyloge-

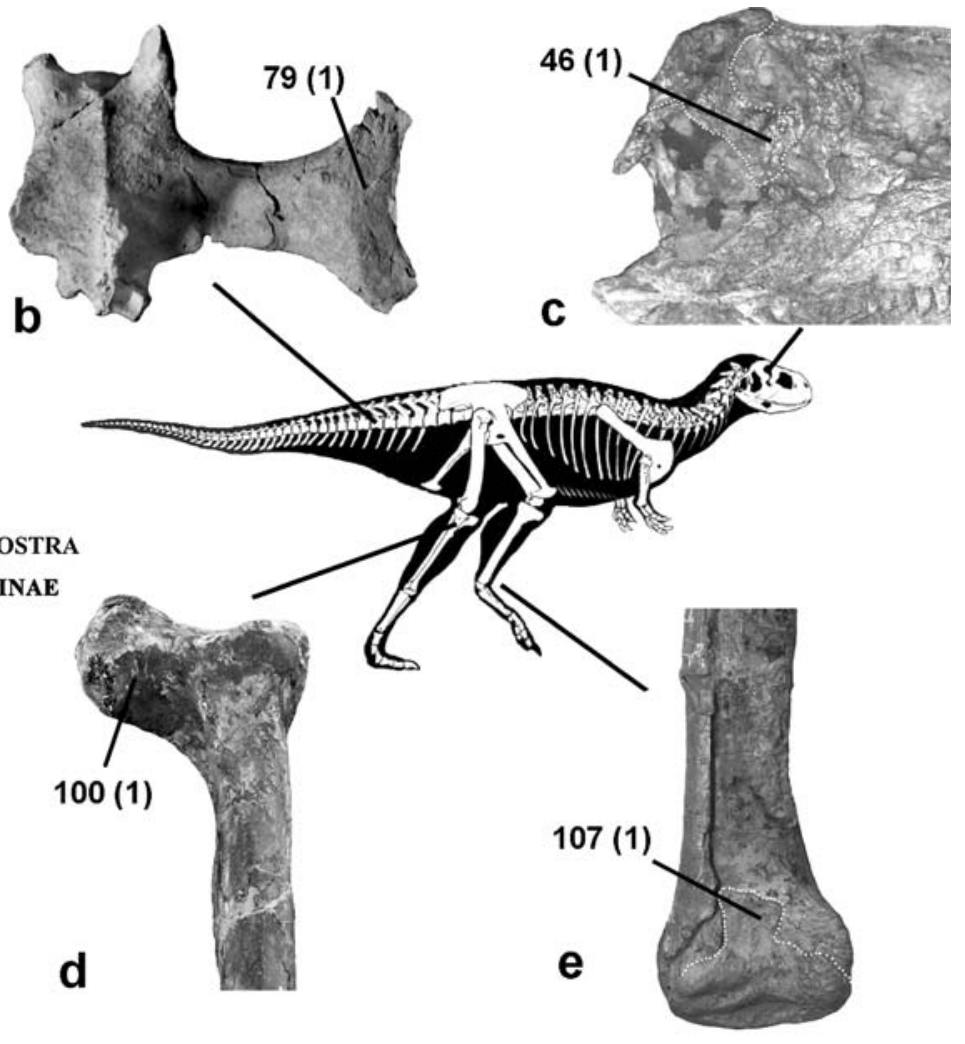

netic analysis). Important anatomical characteristics of Brachyrostrans. $b$ Caudal vertebra of I. aguadagrandensis. $c$ Right lateral view of $S$. bustingorryi skull. $d$ Proximal end of the right tibia of $E$. novasi. $e$ Distal end of left tibia, fibula and astragalus of $A$. garridoi 
includes Carnotaururs, Aucasaurus, Ilokelesia, Ekrixinatosaurus and Skorpiovenator. This clade is termed here Brachyrostra (Fig. 3 b-e; see S1, Emended systematic palaeontology) and is characterised by strongly ornamented and shortened skulls with a progressive enclosure of the orbit. In sharp contrast with previous phylogenetic hypotheses (Coria and Salgado 2000; Sereno et al. 2004; Carrano and Sampson 2008), Ilokelesia is nested among derived abelisaurids, with the Malagasy form, Majungasaurus, as the sister taxon of Brachyrostra. It has been suggested (Sereno et al. 2004) that the presence of frontal horn-like structures represent an apomorphy of Carnotaurinae (Rajasaurus + (Majungasaurus + Carnotaurus) $)$. Nevertheless, the horn-like prominences present in abelisaurid taxa differ in position as well as in bone composition (i.e. a single frontal prominence in Majungasaurus, a pair of frontal horns in Carnotaurus, and dorsally inflated postorbital bones in Skorpiovenator and Ekrixinatosaurus), which challenges homology of this feature.

Abelisaurids were considered a key taxon for mutually exclusive palaeobiogeographical interpretations, namely the "pan-Gondwana model", which suggest connections between major Gondwanan landmasses during the Early Cretaceous before all were finally severed at the beginning of the Late Cretaceous (Sereno et al. 2004), and the "Africa-first model", which support close connections between South America and Indo-Madagascar (but not Africa) well into the Late Cretaceous (Sampson et al. 1998; see Krause et al. 2007, for a comprehensive review of these hypotheses). The recovery of an abelisaurid clade (Brachyrostra) that exclusively occurred in South America, suggests an alternative third model for abelisaurid diversification, i.e. that at least from the Cenomanian through the Maastrichtian, derived South American abelisaurids may have remained isolated from their African and Indo-Madagascar relatives. Such an alternative model is in concordance with palaeogeographical reconstructions of the sequence of isolation of the Gondwanan landmasses (Krause et al. 2007), but does not necessarily apply to the diversification of the remaining Cretaceous terrestrial tetrapods from Gondwana.

The discovery of Skorpiovenator also helps to clarify the chronostratigraphical distribution of other Gondwanan theropods, such as carcharodontosaurids. These were large-sized predatory dinosaurs that some authors (i.e. Veralli and Calvo 2004; Apesteguía et al. 2004; Martinelli and Forasiepi 2004; Candeiro et al. 2006) interpreted as surviving into the latest Cretaceous times. Such assumption was based on small-sized, carcharodontosaurid-like teeth collected in post-Cenomanian beds. However, these purportedly carcharodontosaurid teeth exhibit several features that are also present in Skorpiovenator among abelisaurids, such as straight dental crowns and well-demarkated enamel wrinkles (Fig. 2c, d, e). Thus, we consider the record of post-Cenomanian carcharodontosaurids as dubious. Given the possibility that these teeth actually represent abelisaurids, they cannot be used to contradict an early Late Cretaceous (Cenomanian) extinction of carcharodontosaurids in South America, as hypothesised by Novas et al. (2005).

Acknowledgements We thank C. Albornoz, M. Berrondo, J. Castro, M. Castro, N. Gonzalez, A. Moretti, J. Ochoa, M. Ripoll, M. Soto, and R. Zapata for the excavation and preparation of the specimen; J. Ochoa for his detailed drawings; A. Haluza for their useful comments in early drafts of the manuscript; J. Calvo, R. Coria, A. Kramarz, C. Muñoz and J. Powell for access to specimens under their care; R. Candeiro and A. Martinelli for providing useful pictures of theropod teeth; and Matthew Lamanna and two anonymous reviewers for the useful comments they made that improved the quality of this paper. The Municipalidad of Villa El Chocón is thanked for their constant support. Financial assistance was received from Agencia Nacional de Promoción Científica y Técnica (PICTs 13.803 and 58) and Conicet (PIP 5153).

\section{References}

Apesteguía S, Candeiro R, Agnolín F (2004) Late Cretaceous dwarf carcharodontosaurids in Patagonia. Ameghiniana 41:6R

Bonaparte JF (1991) The gondwanian theropod families Abelisauridae and Noasauridae. Hist Biol 5:1-25

Bonaparte JF, Novas FE (1985) Abelisaurus comahuensis, n. g., n. sp., Carnosauria del Cretácico tardío de Patagonia. Ameghiniana 21:259-265

Bonaparte JF, Novas FE, Coria RA (1990) Carnotaurus sastrei Bonaparte, the horned, lightly built carnosaur from the middle Cretaceous of Patagonia. Contr Sci, Nat Hist Mus Los Angeles Cty 416:1-42

Calvo JO, Rubilar-Rogers D, Moreno K (2004) A new Abelisauridae (Dinosauria: Theropoda) from northwest Patagonia. Ameghiniana 41:555-563

Candeiro CRA, Martinelli AG, Avilla LS, Rich TH (2006) Tetrapods from the upper cretaceous (Turonian-Maastrichtian) Bauru Group of Brazil: a reappraisal. Cret Res 27:923-946

Carrano MT (2007) The appendicular skeleton of Majungasaurus crenatissimus (Theropoda: Abelisauridae) from the Late Cretaceous of Madagascar. J Vert Paleontol 27(suppl: mem 8):163-179

Carrano MT, Sampson SD (2008) The phylogeny of Ceratosauria (Dinosauria: Theropoda). J Syst Paleontol 6:183-236

Carrano MT, Sampson SD, Forster CA (2002) The osteology of Masiakasaurus knopfleri, a small abelisauroid (Dinosauria: Theropoda) from the Late Cretaceous of Madagascar. J Vert Paleontol 22:510-534

Corbella H, Novas FE, Apesteguía S, Leanza HA (2004) First fissiontrack age for the dinosaur-bearing Neuquén Group (Upper Cretaceous), Neuquén Basin, Argentina. Rev Mus Argent Cienc Nat 6:227-232

Coria RA, Salgado L (2000) A basal Abelisauria Novas, 1992 (Theropoda-Ceratosauria) from the Cretaceous of Patagonia, Argentina. GAIA 15:89-102

Coria RA, Currie PJ (2006) A new carcharodontosaurid (Dinosauria, Theropoda) from the Upper Cretaceous of Argentina. Geodivers 28:71-118

Coria RA, Chiappe LM, Dingus L (2002) A new close relative of Carnotaurus sastrei Bonaparte 1985 (Theropoda: Abelisauridae) 
from the Late Cretaceous of Patagonia. J Vert Paleontol 22:460 465

Kellner AWA, Campos DDA (2002) On a theropod dinosaur (Abelisauria) from the continental Cretaceous of Brazil. Arq Mus Nac, Rio de Janeiro 60:163-170

Krause DW, Sampson SD, Carrano MT, O'Connor P (2007) Overview of the history of discovery, taxonomy, phylogeny, and biogeography of Majungasaurus crenatissimus (Theropoda: Abelisauridae) from the Late Cretaceous of Madagascar. J Vert Paleontol 27(suppl: mem 8):1-20

Martinelli AG, Forasiepi AM (2004) Late Cretaceous vertebrates from the Bajo de Santa Rosa (Allen Formation), Rio Negro, Argentina, with the description of a new sauropod dinosaur (Titanosauridae). Rev Mus Argent Cienc Nat, n. s. 6:257-305

Novas FE, De Valais S, Vickers-Rich P, Rich T (2005) A large Cretaceous theropod from Patagonia, Argentina, and the evolution of carcharodontosaurids. Naturwissenschaften 92:226-230

O'Connor P (2007) The postcranial axial skeleton of Majungasaurus crenatissimus (Theropoda: Abelisauridae) from the Late Cretaceous of Madagascar. J Vert Paleontol 27(suppl: mem 8):127162
Sampson S, Witmer L (2007) Craniofacial anatomy of Majungasaurus crenatissimus (Theropoda: Abelisauridae) from the Late Cretaceous of Madagascar. J Vert Paleontol 27(suppl: mem 8):32-102

Sampson S, Witmer L, Forster C, Krause D, O'Connor P, Dodson P, Rovoavy F (1998) Predatory dinosaur remains from Madagascar: implications for the Cretaceous biogeography of Gondwana. Science 280:1048-1051

Sereno PC, Dutheil DB, Iarochene M, Larsson HC, Lyon GH, Magwene PM, Sidor CA, Varrichio DJ, Wilson JA (1996) Predatory dinosaurs from the Sahara and Late Cretaceous faunal differentiation. Science 272:986-991

Sereno PC, Wilson JA, Conrad JL (2004) New dinosaurs link southern landmasses in the Mid-Cretaceous. Proc R Soc Lond (B) 271:1325-1330

Smith JB (2007) Dental morphology and variation in Majungasaurus crenatissimus (Theropoda: Abelisauridae) from the Late Cretaceous of Madagascar. Soc Vertebr Pal: Memoir 8, J Vertebr Paleontol 27:103-126

Veralli C, Calvo JO (2004) Dientes de terópodos carcharodontosáuridos del Turoniano superior-Coniaciano inferior del Neuquén, Patagonia, Argentina. Ameghiniana 41:587-590 